\title{
Corrosion at low moisture content in both carbonated and chloride polluted concrete - Villa E-1027, a case study
}

\author{
Elisabeth Marie-Victoire ${ }^{1, *}$, Myriam Bouichou ${ }^{2}$ \\ ${ }^{1}$ Laboratoire de Recherche des Monuments Historiques, Centre de Recherche sur la Conservation (CRC-USR 3224), Muséum \\ national d'Histoire naturelle, CNRS, Sorbonne Universités, 29 Rue de Paris, 77420, Champs-sur-Marne, France
}

\begin{abstract}
Corrosion in reinforced concrete is generally attributed to either carbonation or chloride presence in the vicinity of the bars. But in the field of cultural heritage, especially for the most ancient monuments, it is not rare to encounter both carbonated and chloride polluted concrete, inducing heavy corrosion, as was the case in the Villa E-1027 in Roquebrune-Cap-Martin, on the French Mediterranean seashore. The villa was designed by Eileen Gray and Jean Badovici between 1926 and 1929. Due to aggressive environmental conditions and a period of dereliction, the concrete of the villa was quite heavily decayed and a deep restoration was led between 2000 and 2006. But after a little more than 10 years, and despite active maintenance, the villa is again facing corrosion induced decay. Prior to the definition of a new restoration protocol, to better evaluate the corrosion activity, in 2017 a permanent monitoring of moisture and temperature both in the air and in the concrete was installed. In the meantime, a series of instant electrochemical measurements was performed from 2017 to 2018 . A first analysis of the results of the monitoring and the nondestructive tests clearly evidences that probably due to the conjunction of the carbonation of the concrete and external active chloride pollution, corrosion can happen at quite low moisture content..
\end{abstract}

\section{Introduction}

If carbonation induced corrosion and chloride induced corrosion were extensively studied as separate mechanisms [1] [2] [3] [4], research on their combined pollution, which is often encountered in the field of historic concrete, is rare [5]. For the latter, carbonation is usual, and can affect the concrete cover up to several centimetres [6].When chlorides, either linked to sea proximity or to de-icing salts, reach the reinforcing bars, then heavy corrosion can occur. In France, among the 850 historic monuments made of concrete, $27 \%$ are concerned by chloride pollution and most of them are affected by carbonation [7]. The Villa E-1027 is one of those monuments. The purpose of the present research was to study the corrosion mechanisms affecting this villa and to determine the most suitable restoration technique.

\section{Context}

Built between 1926 and 1929 by Eileen Gray and Jean Badovici in Roquebrune-Cap-Martin near Nice, the villa E-1027 faces the Mediterranean sea (Fig.1). Its structural elements and floors are made of concrete, while the nonstructural components are more heterogeneous (bricks...). It was partially rendered and totally covered with a lime wash.

After being abandoned for a long time, in 2000, the villa was decayed in correlation with water infiltration, ground movement and rebar corrosion. A first deep restoration operation was conducted between 2000 and 2006 , including the use of a mineral migrating corrosion inhibitor for the concrete reinforcement and foundation treatments. Nevertheless, eleven years after this restoration and despite periodic maintenance, the concrete was again decaying due to rebar corrosion.

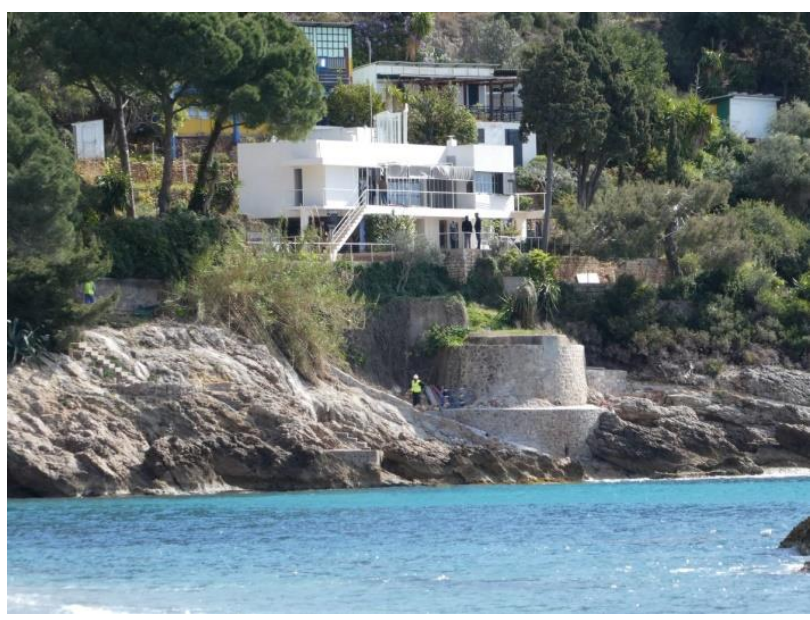

Fig. 1. General view of the Villa E-1027, facing the sea.

The first step of diagnosis performed in 2000 [8], evidenced, for the concrete design, a mix of CEM I cement $\left(300 \mathrm{~kg} / \mathrm{m}^{3}\right)$ and calcareous aggregates with siliceous sand. The performance of this concrete was quite low with an open porosity of $17 \%$ and compressive strengths ranging between 9.6 $\mathrm{MPa}$ (patio beam) and 13.3 MPa (patio pillar). In terms of decay, if carbonation had

* Corresponding author: elisabeth.marie-victoire@ culture.gouv.fr 
exceeded the rebar level in most of the areas examined, moderate external sulfate and chloride pollution were encountered, leading to the formation of Friedel Salts and Ettringite in the cement matrix. Potential mapping evidenced significant gradients in the beams and the underside of the floor of the patio.

A second step of diagnosis was carried out in 2016 [9], showing significant chloride ( 0.05 up to $2.14 \%$ by weight of cement) (Table 1) and alkali pollution (1.19 up to $22.5 \mathrm{eqNa} 2 \mathrm{O} \mathrm{kg} / \mathrm{m}^{3}$ ) on both the patio and the balconies of the villa, and a moderate sulfate pollution ( $1.18 \%$ up to $5.36 \%$ by weight of cement). Carbonation had also progressed (20 to $70 \mathrm{~mm}$ ), and corrosion was still active as confirmed by instant electrochemical measurements performed with a Galvapulse ${ }^{\odot}$ (Table 2).

Table 1. Chloride profiles ( $\% \mathrm{~m} / \mathrm{m}$ of cement) on the pillars of the patio and on the balconies.

\begin{tabular}{|c|c|c|c|c|}
\hline & $\begin{array}{c}0-10 \\
(\mathrm{~mm})\end{array}$ & $\begin{array}{c}10-20 \\
(\mathrm{~mm})\end{array}$ & $\begin{array}{c}20-30 \\
(\mathrm{~mm})\end{array}$ & $\begin{array}{c}30-40 \\
(\mathrm{~mm})\end{array}$ \\
\hline Pillar n² & $0.43 \%$ & $1.85 \%$ & $0.45 \%$ & $0.31 \%$ \\
\hline Pillar n5 & $1.12 \%$ & $1.34 \%$ & $1.83 \%$ & $/$ \\
\hline Pillar n $^{\circ} 9$ & $0.99 \%$ & $0.44 \%$ & $0.45 \%$ & $0.31 \%$ \\
\hline $\begin{array}{c}\text { South } \\
\text { balcony } \\
\text { (Sea side) }\end{array}$ & $1.86 \%$ & $0.26 \%$ & $0.23 \%$ & $0.66 \%$ \\
\hline $\begin{array}{c}\text { East } \\
\text { balcony }\end{array}$ & $0.15 \%$ & $0.05 \%$ & $0.15 \%$ & $/$ \\
\hline $\begin{array}{c}\text { Underside } \\
\text { of the } \\
\text { floor }\end{array}$ & $0.31 \%$ & $2.14 \%$ & $1.45 \%$ & $/$ \\
\hline
\end{tabular}

Table 2. Electrochemical measurements performed with a Galvapulse $($ e equipped with a copper/copper sulfate reference electrode on 3 testing areas of the underside of the southern balcony (Z3) and of the floor of the patio (Z1 and Z2).

\begin{tabular}{|c|c|c|c|c|}
\hline $\begin{array}{c}\text { Testing } \\
\text { area }\end{array}$ & $\begin{array}{c}\text { Potential } \\
\text { min }(\mathrm{mV})\end{array}$ & $\begin{array}{c}\text { Potential } \\
\max (\mathrm{mV})\end{array}$ & $\begin{array}{c}\text { Max } \\
\text { potential } \\
\text { gradient } \\
(\mathrm{mV})\end{array}$ & $\begin{array}{c}\text { Corrosion } \\
\text { current } \\
\left(\mu \mathrm{A} / \mathrm{cm}^{2}\right)\end{array}$ \\
\hline $\mathrm{Z} 1$ & 78 & 224 & 146 & 11 \\
\hline $\mathrm{Z} 2$ & -82 & 136 & 218 & 5.5 \\
\hline $\mathrm{Z} 3$ & -14 & 365 & 379 & 6 \\
\hline
\end{tabular}

Taking into account the results of these 2 steps of diagnosis, the restoration options were limited. The durability of a standard patching operation, combined with a migrating corrosion inhibitor had shown its limits (lower than 10 years). As the chloride pollution was inevitably active, the villa facing the sea, electrochemical chloride extraction could only be a temporary solution. Finally a waterproof paint couldn't be envisaged due to recurrent infiltration problematic in a context of a concrete loaded with different salts (sulfates, chlorides, alkali). The last durable option was cathodic protection. But its invasiveness represented an issue for an historic concrete which has to be as preserved as possible.

Considering this problematic preservation, prior to the final choice of restoration strategy and taking into account that complementary maintenance work had just been performed to eradicate some infiltration problems on the balconies that had also an impact on the concrete of the patio, a last phase of diagnosis was scheduled with the aim of evaluating the residual corrosion activity on the balconies and the patio (Fig. 2), after this maintenance. Two types of analysis were considered: instant electrochemical measurements and permanent monitoring over one year.

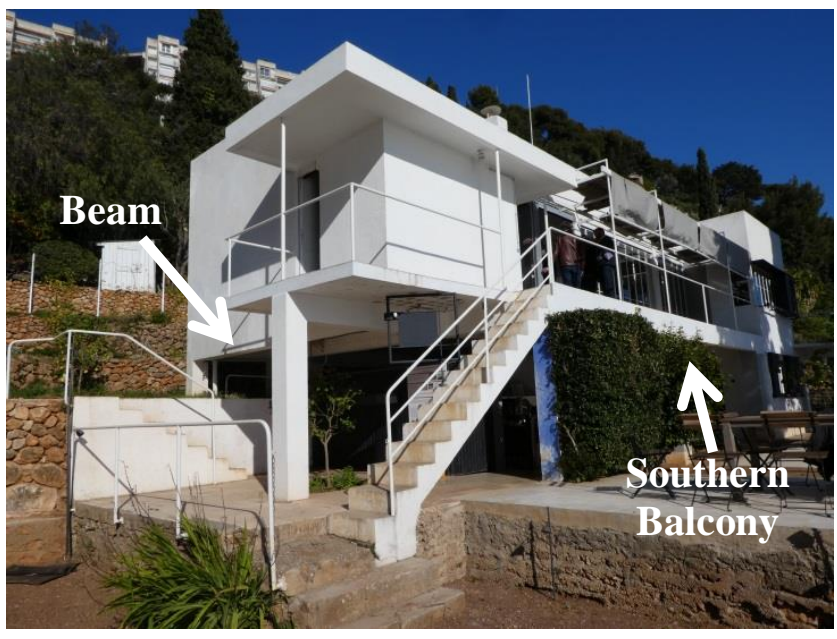

Fig. 2. Detailed view of the patio.

\section{Analytical protocol}

\subsection{Non-destructive testing}

Three types of non-destructive testing were carried out: resistivity mapping, potential mapping, and polarization resistance measurements, using a Proceq ${ }^{\complement}$ corrosimeter and a Gecor $10^{\circ}$, both equipped with copper-copper sulfate reference electrodes. Tests were performed 4 times between 2017 and 2018, respectively in April 2017 and March, June and October 2018 (Table 3). Three zones selected on step 2 of the diagnosis were considered (Z1, Z2, Z3, plus a beam of the patio), but only the results obtained in zone 3 (southern balcony) and on a beam of the patio (partially cracked due to corrosion), which are representative of all the measurements, will be presented in this paper. In each zone, polarization resistance was measured on two points corresponding to potential and resistivity gradients.

Table 3. Environmental conditions at the testing dates.

\begin{tabular}{|c|c|c|c|c|}
\hline Date & $25 / 04 / 2017$ & $01 / 03 / 2018$ & $26 / 06 / 2018$ & $15 / 10 / 2018$ \\
\hline $\begin{array}{c}\mathrm{T} \\
\left({ }^{\circ} \mathrm{C}\right)\end{array}$ & 16 & 6.8 & 24.3 & 22.6 \\
\hline $\begin{array}{c}\mathrm{RH} \\
(\%)\end{array}$ & 76 & 78 & 67 & 59 \\
\hline
\end{tabular}




\subsection{Permanent monitoring}

For the permanent monitoring, 2 active corrosion spots previously identified by non-destructive testing were selected respectively on a beam of the patio and on the underside of the southern balcony (Z3). Three types of measurements were considered:

- Temperature and relative humidity in the air (weather station, Fig. 4),

- Temperature and relative humidity in the concrete (Vaisala ${ }^{\odot}$ sensors, Fig. 3),

- Resistance, potential and polarization resistance (dedicated sensor designed by the Spanish company Sensecorr, Fig. 3) equipped with manganese/ manganese oxide reference electrodes.

All the sensors were connected to a data acquisition system remotely interrogated by cell phone (Fig. 4)

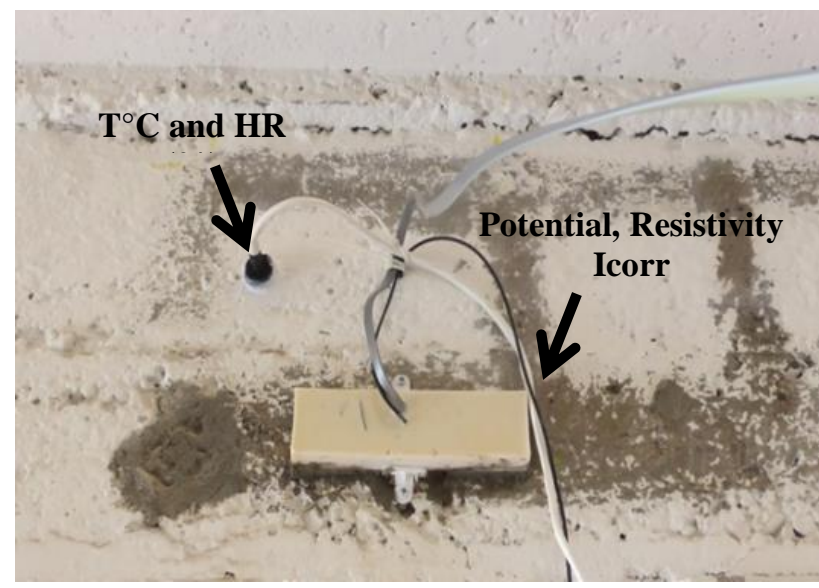

Fig. 3. Temperature, relative humidity and corrosion sensors.

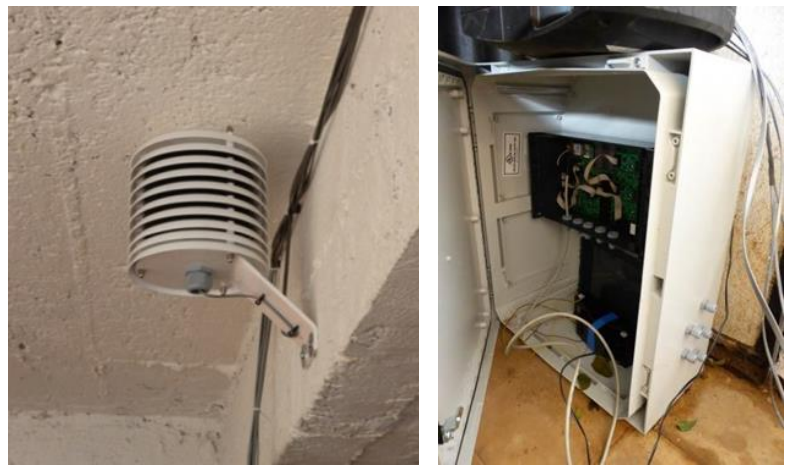

Fig. 4. Weather station (left) and data acquisition system remotely accessible (right).

\section{Results}

\subsection{Non-destructive testing}

\subsubsection{Balcony}

The first map of resistivity performed in April 2017 on the underside of the southern balcony (Fig. 5), was indicative of an overall moderate risk of corrosion according to the RILEM recommendation [10], with values ranging between 9 and $124 \mathrm{k} \Omega . \mathrm{cm}$ and an average of $43 \mathrm{k} \Omega . \mathrm{cm}$.

On the potential map (Fig. 6) significant gradients [11] (average value: $-196 \mathrm{mV}$, maximum gradient: $160 \mathrm{mV}$ ) could be observed on the lower zone of the map and especially on the point C6.

Polarization resistance measurements were performed on two points of the lower part of the zone and were indicative of a high level of corrosion according to the RILEM Recommendation [12] (C3: $\left.1.550 \mu \mathrm{A} / \mathrm{cm}^{2} ; \mathrm{C} 4: 1.213 \mu \mathrm{A} / \mathrm{cm}^{2}\right)$.

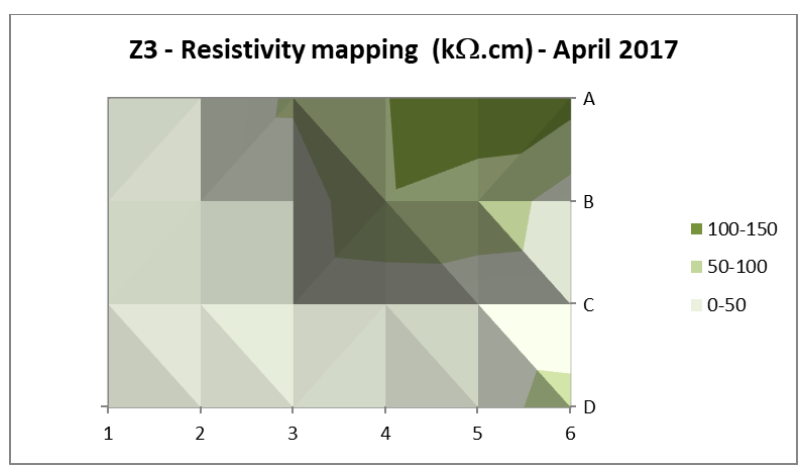

Fig. 5. Resistivity mapping obtained on zone 3 in April 2017.

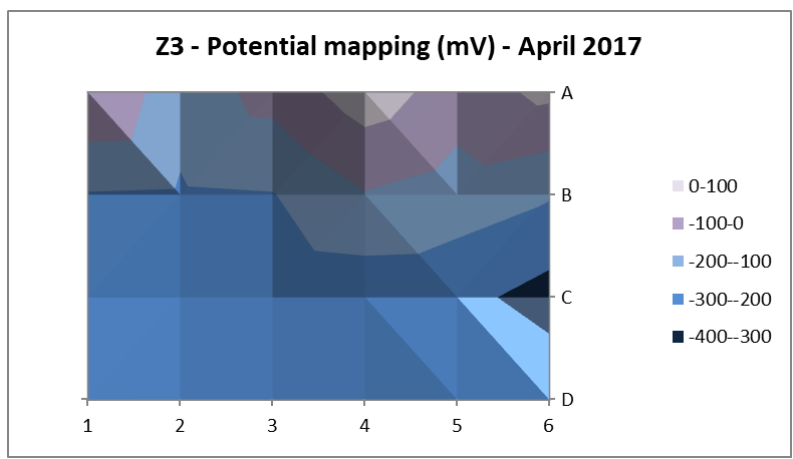

Fig. 6. Potential mapping obtained on zone 3 in April 2017.

On the following three series of measurements performed in March, June and October 2018, almost similar resistivity and potential maps were observed, with nevertheless an increase of corrosion risk on the lower part of the beam (Fig. 7). A clear correlation could be observed between the evolution of the relative humidity in the air and the resistivity and potential values. Thus, when the relative humidity decreases, the resistivity increases and the potentials tend to less electronegative values (Fig. 8 and 9).

The same tendencies were observed for the corrosion currents except in June 2018, where the higher values were obtained (Fig. 10). This could be linked to connection difficulties encountered during the tests that lead to a repetition of the measurements and to an increased moistening of the concrete in points $\mathrm{C} 3$ and C4. But during the period of measurement, that lasted one year and a half, the corrosion current on the balcony was indicative of a corrosion level varying between moderate and high. 


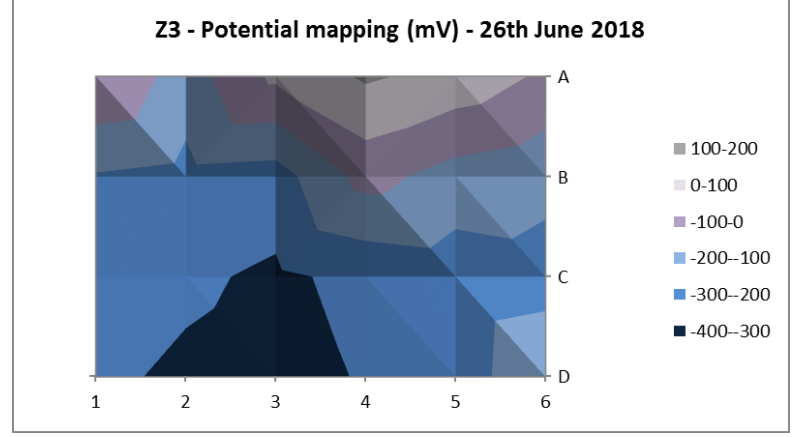

Fig. 7. Potential mapping obtained on zone 3 on June 2018.

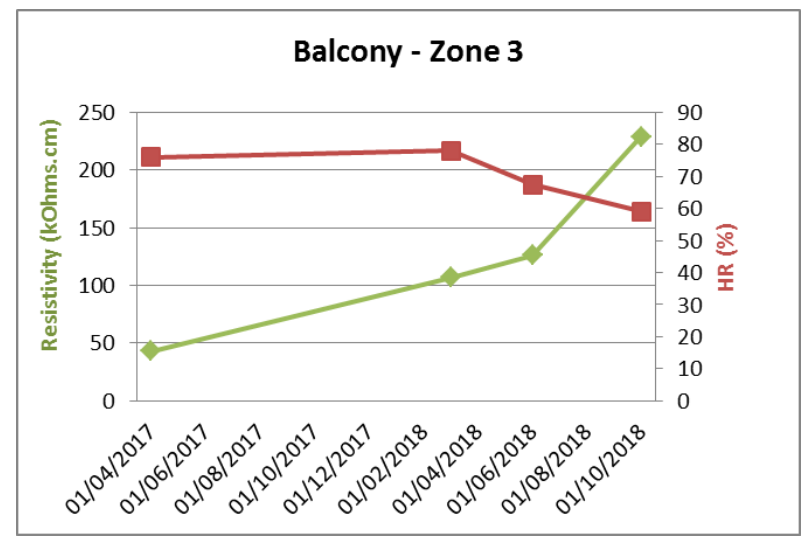

Fig. 8. Evolution of the average resistivity in zone 3 and of the relative humidity in the air.

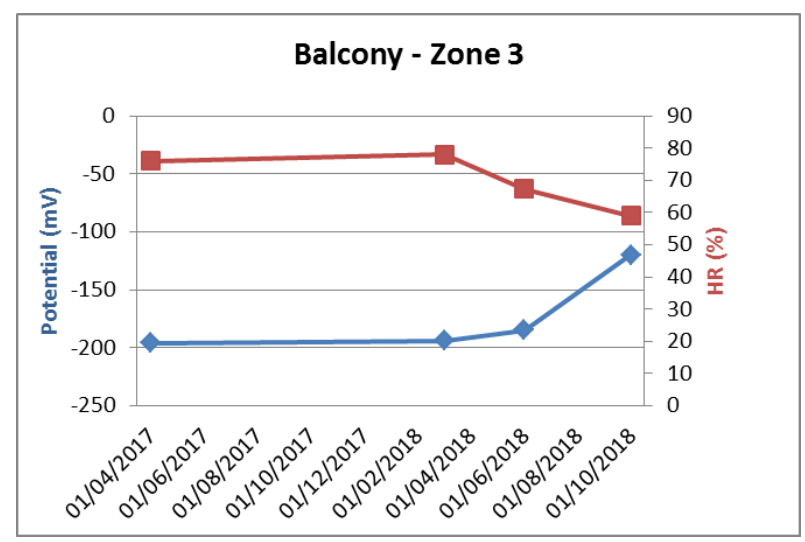

Fig. 9. Evolution of the average potential in zone 3 and of the relative humidity in the air.

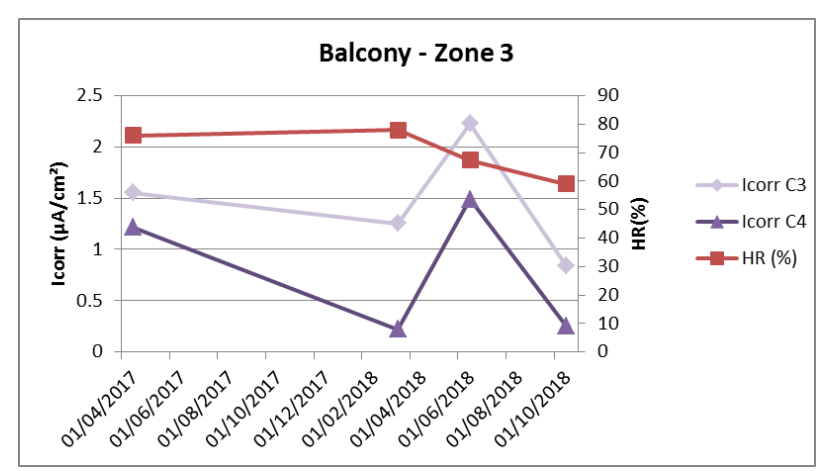

Fig. 10. Evolution of the average corrosion current in zone 3 and of the relative humidity in the air.

\subsubsection{Beam}

On the beam, the resistivity measured was a little higher than in zone 3 and indicative of a risk of corrosion varying from negligible [10] on the upper part of the beam, to moderate on the lower part (Fig. 11). The values ranged between 28 and $176 \mathrm{k} \Omega . \mathrm{cm}$ and an average of $109 \mathrm{k} \Omega . \mathrm{cm}$.

The potential map (Fig. 12) was consistent with the resitivity mapping, indicating a probable risk of corrosion [11] on the lower part of the beam (average value: $-230 \mathrm{mV}$, maximum gradient: $95 \mathrm{mV}$ ). Nevertheless, as for zone 3 , it is to be noticed that the potential values are not very electronegative for a concrete both carbonated and chloride polluted.

Polarization resistance measurements were performed at two locations identified on the potential map, on the lower part of the beam. They were indicative of a low level of corrosion [12] (B23: $0.140 \mu \mathrm{A} / \mathrm{cm}^{2} ; \mathrm{C} 4$ : $\left.0.204 \mu \mathrm{A} / \mathrm{cm}^{2}\right)$.

As for the balcony area, similar results were observed on the three following three series of measurements, with again a clear correlation between the evolution of the relative humidity in the air and that of the resistivity and potential (Fig. 13 and 14). If the corrosion currents measured at point B12 were also well correlated (Fig. 15) and indicative of a negligible level of corrosion, at point B23 a continuous increase of the corrosion current could be noticed, in correlation with the opening of a crack (Fig. 16).

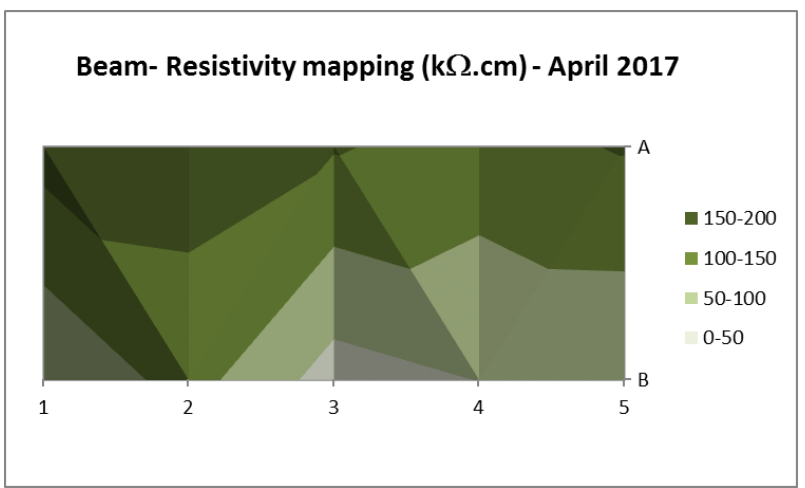

Fig. 11. Resistivity mapping obtained on the beam on April 2017.

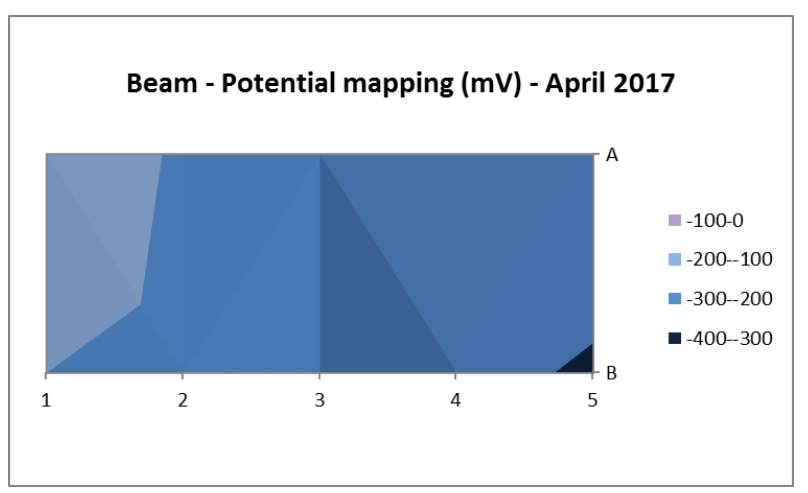

Fig. 12. Potential mapping obtained on the beam in April 2017. 


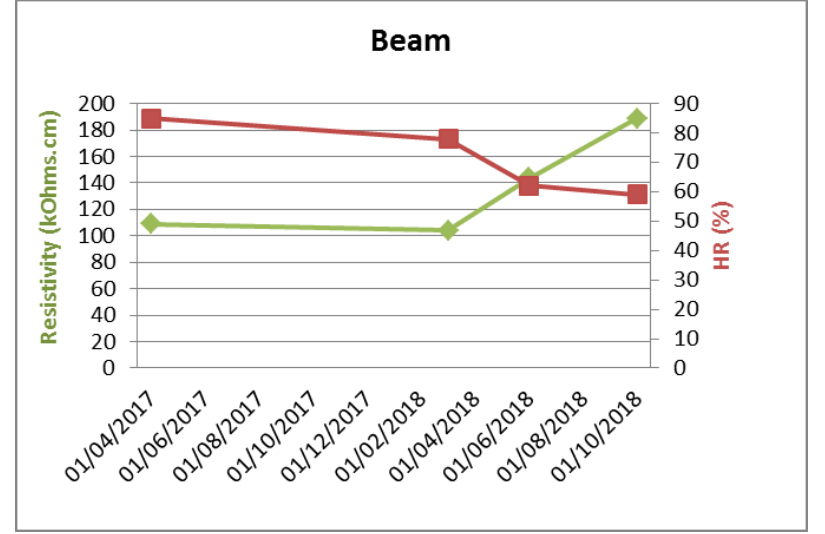

Fig. 13. Evolution of the average resistivity in the beam and of the relative humidity in the air.

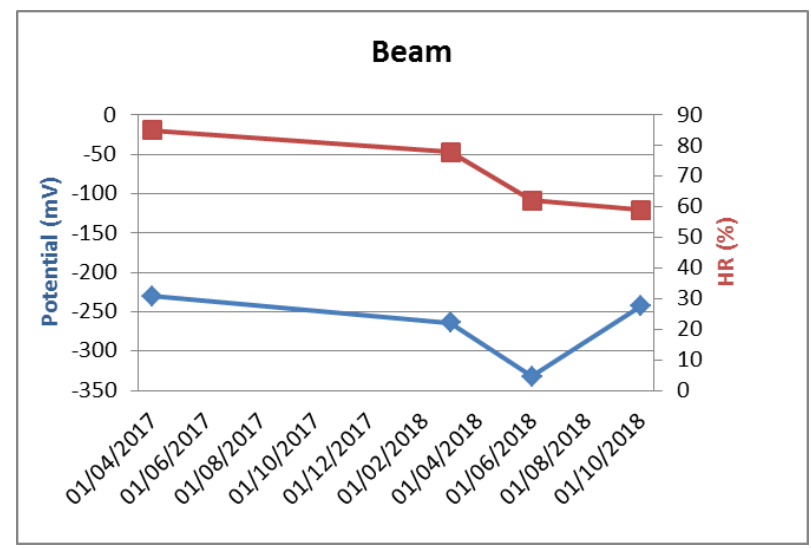

Fig. 14. Evolution of the average potential on the beam and of the relative humidity in the air.

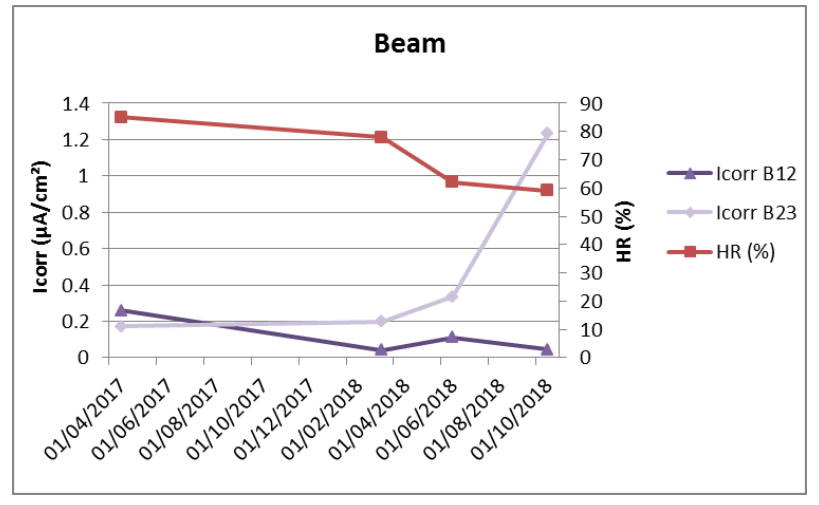

Fig. 15. Evolution of the average corrosion current on the beam and of the relative humidity in the air.

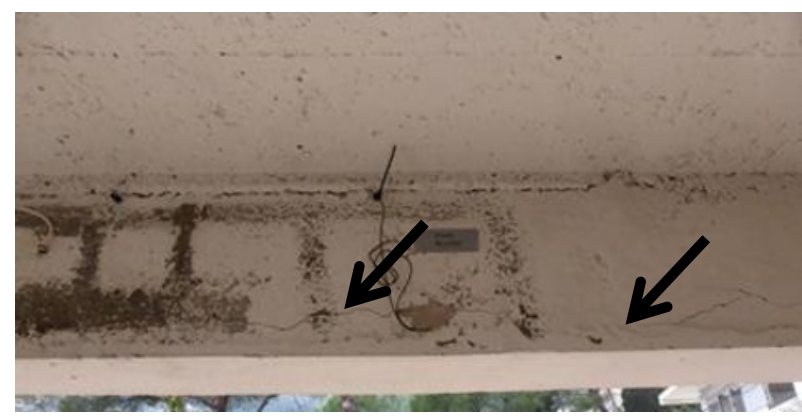

Fig. 16. Opening of a crack on the beam in the vicinity of the measurement point B23.

\subsection{Monitoring}

Data were recorded between April 2017 and September 2018.

\subsubsection{Temperature}

As can be observed on Fig. 17, the temperature measured in the concrete either under the balcony or in the beam, are very similar but also very close to that measured in the air. The three curves are overlapping. During the monitoring period, temperatures in the concrete ranged between 0.5 and $33^{\circ} \mathrm{C}$, with a maximum daily amplitude of $5^{\circ} \mathrm{C}$.

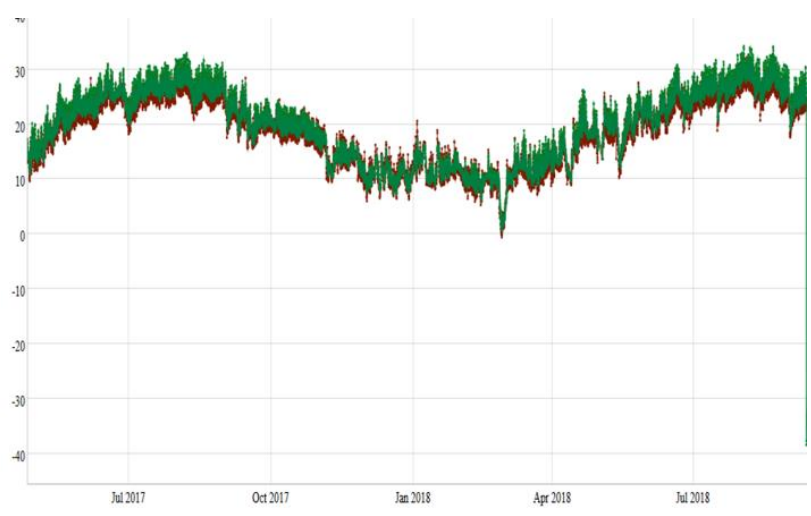

Fig. 17. Temperature $\left({ }^{\circ} \mathrm{C}\right)$ in the air (brown curve) and in the concrete in the balcony and in the beam (green curve).

\subsubsection{Relative humidity}

Contrary to the temperature, relative humidity in the air and in the concrete was clearly distinct. Thus it fluctuated a lot in the air, while it was much more stable in the concrete (Fig. 18), which was already observed by several authors [13]. When comparing the results obtained in the 2 zones monitored, it appears that the relative humidity was slightly higher but also less fluctuating in the beam (average: 68\%) than in the balcony (average: 63\%). Globally, the relative humidity in the concrete was lower in winter and higher in spring. Thus, in the beam, the maximum was reached the $13^{\text {rd }}$ of June $2018(78 \%)$ and the minimum in December 2017 $(60 \%)$. On the Balcony, the maximum was observed on the $21^{\text {st }}$ of June $2018(77 \%)$ and the minimum in December 2017 (53\%).

\subsubsection{Electrochemical monitoring}

As the two zones monitored were protected from the rain, electrochemical monitoring was an issue. Effectively, the contact mortar used between the sensors and the concrete gradually dried and the measurements became impossible, quite rapidly for the beam and soon after for the balcony (Fig. 19). Nevertheless, the first data were consistent with the non-destructive testing, with corrosion current values lower in the beam than in the balcony (Fig. 20). 


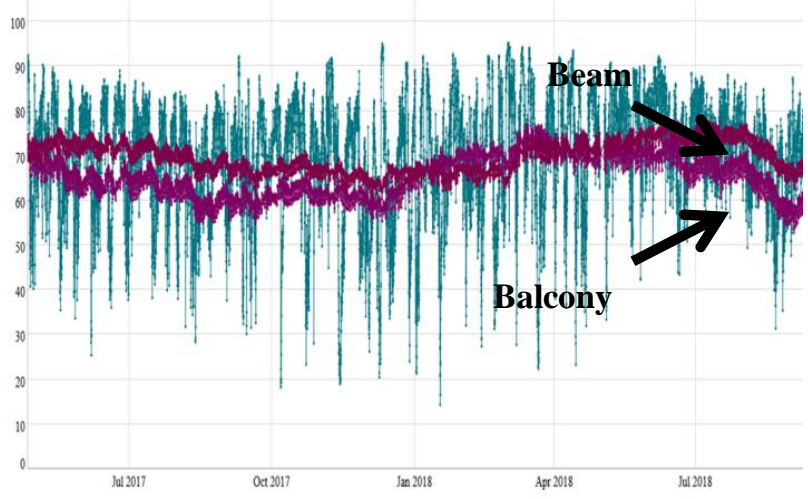

Fig. 18. Relative humidity (\%) in the air (blue curve) and in the concrete in the balcony and in the beam (purple curve).

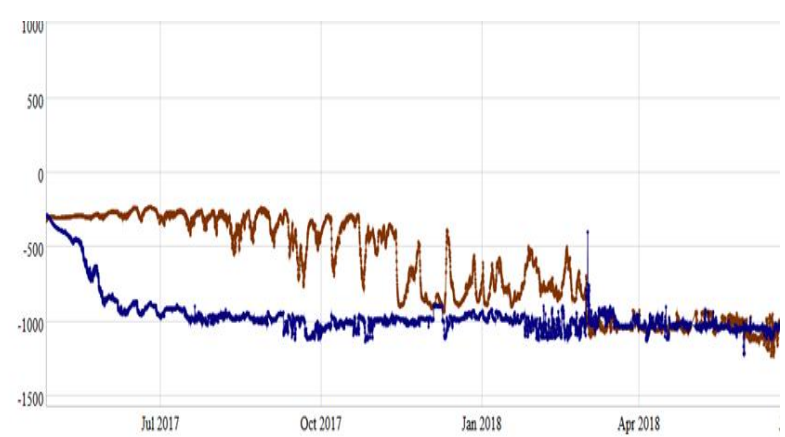

Fig. 19. Potential (mV) on the balcony (ochre curve) and on the beam (blue curve).

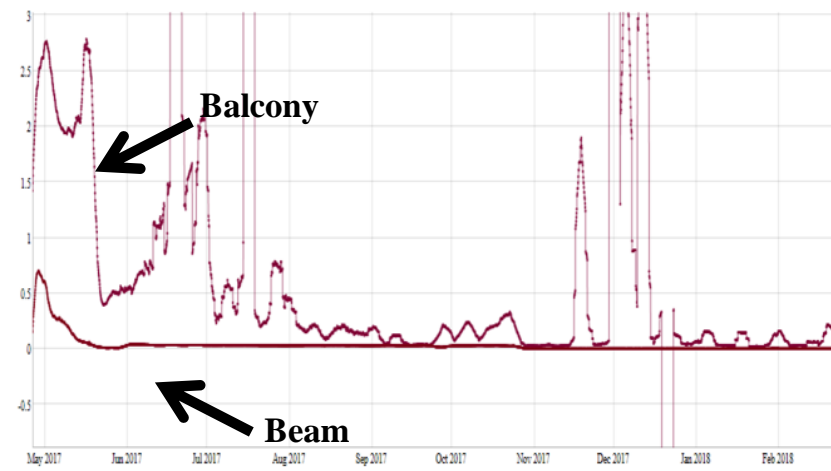

Fig. 20. Corrosion current $\left(\mu \mathrm{A} / \mathrm{cm}^{2}\right)$ on the balcony and on the beam.

\section{Discussion}

Due to contact mortar issues in the testing zones which were protected from the rain, electrochemical monitoring couldn't be performed during the year and a half initially scheduled. Nevertheless, the temperature and relative humidity monitoring evidenced a certain stability in the concrete on the two zones examined (Fig. 21) both on a daily and a yearly basis, so that the non-destructive instant electrochemical measurements could be extrapolated to the whole year, and were indicative of active corrosion in both the balcony and the beam examined.

As the testing zones were sheltered from the rain, the relative humidity in the concrete was quite low (yearly average between 63 and 68\%). Several studies evidenced a critical threshold of relative humidity between $60 \%$ and $70 \%$, below which corrosion is supposed to be negligible [14] [15]. On this basis, the corrosion currents observed on the 2 tested zones of the villa could be surprising. But other authors evidenced that this threshold can vary depending on the exposure of the concrete (rain and temperature...) [13], and the carbonation and/or chloride pollution of the concrete [3]. Thus for a carbonated concrete, depending on the chloride content the relative humidity below which corrosion is negligible, can decrease to $40 \%$ [3]. This could be linked to both the hygroscopicity of the chloride salts and to the aggressiveness of the combined carbonation and chloride pollution for the corrosion of reinforcing bars.

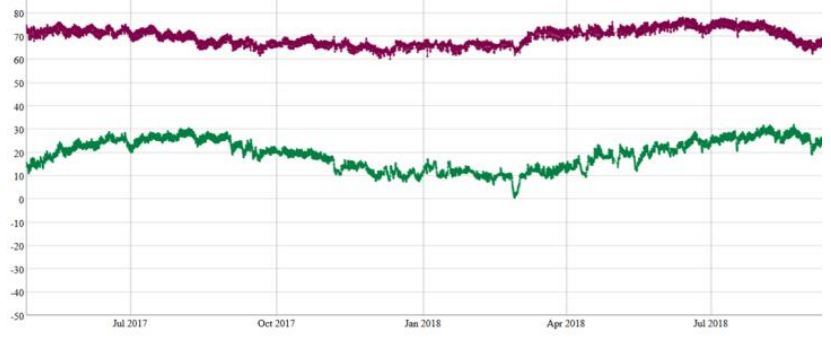

Fig. 21 Temperature $\left({ }^{\circ} \mathrm{C}\right.$, green curve $)$ and relative humidity $(\%)$ in the beam (purple curve).

\section{Conclusions}

Eleven years after a massive restoration of the Villa E1027 built in the late 1920's on the French Mediterranean seashore, due to corrosion of the rebars a new repair operation was planned in 2016. Prior to the elaboration of the restoration strategy, a series of analyses were set up in order to evaluate the levels of carbonation and chloride pollution and to try to quantify the corrosion activity. The diagnosis combined chemical analysis, environmental parameters follow-up and electrochemical measurements. The latest included instant non-destructive testing and monitoring for 18 months.

The results of this diagnosis evidenced active corrosion induced by combined carbonation and chloride pollution, despite a low yearly average relative humidity in the concrete.

As a consequence, the possible durable restoration strategies were limited to one option: cathodic protection. But as this technique can be quite invasive and in addition difficult to implement in historic concrete due to an erratic and non-connected rebar network, a pilot impressed current cathodic protection was installed on a beam, a pillar and $1 \mathrm{~m}^{2}$ of the southern balcony underside. The purpose was to try to limit the cuts and holes to respect the conservation principle of historic monuments and to follow-up the efficiency of such a treatment during 6 months, prior to the installation of the system on the whole patio. 


\section{Acknowledgements}

The authors would like to thank the French ministry of Culture for their financial support and their interest in the project (specially Mr. Christophe Curial from DRAC-PACA), but also the Sensecorr and Freyssinet companies for their technical support, Mrs. Carmen Andrade for her expertise and her help, the architect in charge of the project (Mrs. Claudia Devaux), and the association Capmoderne in charge of the management of the villa.

\section{References}

1. M. Thiéry, "Modélisation de la carbonatation atmosphérique des matériaux cimentaires", Ouvrage d'art OA52, Etudes et recherches des Laboratoires des Ponts et Chaussées, Laboratoire des Ponts et Chaussées, Paris, 337p, (2006)

2. M. Hergenroeder, R. Rackwitz, "Investigations on the statistics of carbonation depths in concrete", 2nd International RILEM/CEB symposium on quality control of concrete structures, Ghent, pp. 451-460, (1991)

3. L. Bertolini, B. Elsner, P. Pedeferri, R. Polder, Corrosion of steel in concrete, Wiley-VCH, Weinheim, Germany, 392p (2004)

4. U. Angst, B. Elsener, C.K. Larsen, O. Vennesland, Critical chloride content in reinforced concrete - A review. Cement and Concrete Research, 39, 11221138 (2009)

5. J. Mai-Nhu, « Corrosion des armatures du béton : couplage carbonatation/chlorures en présence de cycles hydriques », thèse de doctorat de l'université de Toulouse, Toulouse, France, 244p (2013)

6. E. Marie-Victoire, E. Cailleux, A. Texier, Carbonation and historical buildings made of concrete, , In Journal de physique IV, Proceedings of NUCPERF 2006: Corrosion and long term performance of concrete in NPP and waste facilities, 27-30 March 2006, Cadarache, France, EFC Event 284, vol. 136, p. 305-318 (2006)

7. E. Marie-Victoire, M. Bouichou, T. Congar, R. Blanchard, Concrete cultural heritage in France: inventory and state of conservation, In Concrete repair, rehabilitation and retrofitting IV: Proceedings of the 4th international conference on concrete repair, Rehabilitation and Retrofitting (ICCRRR-4), Leipzig, Germany (2015)

8. A. Boule, Rapport LERM n00.5048.001.01.A, Arles, France, 34p (2007)

9. M. Renouard-Opigez, Rapport CEBTP $\mathrm{N}^{\circ}$ CNI7.G.229, Nice, France, 104p (2016)

10. R. Polder with contributions from C. Andrade, B. Elsener, O. Vennesland, J. Gulikers, R. Weidert and M. Raupach, RILEM TC 154-EMC, Recommendations: Test methods for on-site measurement of resistivity of concrete, Materials and Structures, 33, pp 303-611 (2000)
11. B. Elsener with contributions from C. Andrade, J. Gulikers, R. Polder and M. Raupach , RILEM TC 154-EMC, Recommendations: Half-cell potential measurements - Potential mapping on reinforced concrete structures, Materials and Structures, 36, pp 461-471 (2003)

12. C. Andrade and C. Alonso with contributions from J. Gulikers, R. Polder, R. Cigna, O. Vennesland, M. Salta, A. Raharinaivo and B. Elsener, RILEM TC 154-EMC, Recommendations: Test methods for onsite corrosion rate measurement of steel reinforcement in concrete by means of the polarization resistance method, Materials and Structures, 37, pp 623-643 (2004)

13. C. Andrade, C. Alonso, J. Sarría, Corrosion rate evolution in concrete structures exposed to the atmosphere, Cement \& Concrete Composites, 24, p. 55-64, (2002)

14. K. Tuutti, Corrosion of steel in concrete, Swedish cement and concrete institute, Stockholm, Sweden, 473p (1982)

15. J.N. Enevoldsen, C.M. Hansson, The influence of internal relative humidity on the rate of corrosion of steel embedded in concrete and mortar, Cement and Concrete Research, 24, pp. 1373-1382, (1994) 